\title{
Margaret McCartney: Mindful of mindfulness
}

\author{
Margaret McCartney general practitioner, Glasgow
}

Are you paying attention to the present moment, in a non-judgmental way? Are you undistracted? Do you feel "here" and grounded?

The modern mindfulness movement has gained wide support in Britain, far beyond its use in mental health services. But the National Institute for Health and Care Excellence approves the technique only for preventing and treating some mental illnesses.

Mindfulness has become the realm of smartphone apps and courses in community halls and workplaces-including, reportedly, the US military and Google. And BT's wellbeing adviser said that mindfulness can help foster a "resilient workforce."1

Mindfulness is also used in schools. Here, in particular, impressive promises are made. It's for "the flourishing of young minds." ${ }^{2}$ It will enable schoolchildren to experience greater wellbeing, to fulfil their potential, and to improve their concentration and focus. ${ }^{3}$ Courses offer to reduce exam stress. ${ }^{4}$ The UK Mindfulness All Party Parliamentary Group recently made its recommendations for education. It wants three schools to "pioneer mindfulness teaching," test models of "replicability," and disseminate best practice. It wants $£ 1 \mathrm{~m}$ a year to "train teachers in mindfulness." 5

Using mindfulness in workplaces may seem attractive-make your employees resilient. But fair wages and a smaller workload may help more. Taking time to relax, talk to colleagues, think, and reflect is part of humanness; however, trials of mindfulness have generally used waiting lists or usual care as control groups rather than testing against other interventions. ${ }^{6}$ What of the benefit of shared coffee times among general practice staff in reducing stress, for example, or an end to unwanted zero hours contracts? And what of the practice's long term outcomes?

Similar problems exist with using mindfulness in schools. A recent systematic review found much unpublished literature, an asymmetric funnel plot (with a possible rational explanation, but still), and a lack of long term follow-up or control groups that used other means of relaxation or stress reduction. ${ }^{7} \mathrm{No}$ wonder, then, that its conclusion called for better research.

Yet the all party group is urging the Department for Education to fund voluntary and private providers to start online programmes in mindfulness, as well as to train mental health "leads" in schools. The group seems to be calling for a revolution.

But how can mindfulness help children who arrive at school hungry, whose parents are on zero hour contracts and have had tax credits withdrawn? How about comparing outcomes of mindfulness practice with providing free school meals or safe spaces to play?

Mindfulness, applied to the population rather than to people who are or have been mentally ill, risks making individuals responsible for their resilience, even though the systemic problems of social inequality are to blame. This is not to say that mindfulness, or another form of relaxation, may not be useful or important. But we must demand better evidence before making policy.

\section{Competing interests: See www.bmj.com/about-bmj/freelance- contributors/margaret-mccartney.}

Provenance and peer review: Commissioned; not externally peer reviewed.

thebmj.com Personal View Use hand cleaning to prompt mindfulness in clinic (BMJ 2016;352:i13, doi:10.1136/bmj.i13)

Macaro A, Baggini J. Businesses on the mindfulness bandwagon. Financial Times 2015 Mar 13.

2 Fort-Catanese K. For the flourishing of young minds: developing a mindful school culture. Huffington Post2014 Sep 5. www.huffingtonpost.co.uk/krysten-fortcatanese/developing a-mindful-school-culture b 5763266 .html.

3 Mindfulness in Schools Project. What is .b, pronounced [dot-be]? https:// mindfulnessinschools.org/what-is-b/b-curriculum/.

4 Mind Space. Mind space tips for dealing with exam stress. Guardian 2013 Jun 18. http:/ /teachers.theguardian.com/teacher-resources/13320/Mind-Space-Tips-for-Dealing-withExam-Stress.

5 Mindfulness All-Party Parliamentary Group (MAPPG). Mindful nation UK. Oct 2015. http: //themindfulnessinitiative.org.uk/images/reports/Mindfulness-APPG-Report_Mindful-NationUK_Oct2015.pdf.

6 De Vibe M, Bjørndal A, Tipton E, Hammerstrøm K, Kowalski K, et al. Mindfulness based stress reduction (MBSR) for improving health, quality of life, and social functioning in adults. Jan 2012; doi:10.4073/csr.2012.3.

7 Jenner C, Herrnleben-Kurz S, Walach W. Mindfulness-based interventions in schools-a systematic review and meta-analysis. Front Psychol 2014:5:603. 